\section{EMBRYRIDDLE}

Aeronautical University

SCHOLARLY COMMONS
Journal of Aviation/Aerospace

Education \& Research

Volume 13

Number 3 JAAER Spring 2004

Article 1

Spring 2004

\title{
Adaption and Innovation in Flight Training - The Benefits of Cognitive Diversity
}

Kurt Barnhart

Follow this and additional works at: https://commons.erau.edu/jaaer

\section{Scholarly Commons Citation}

Barnhart, K. (2004). Adaption and Innovation in Flight Training - The Benefits of Cognitive Diversity. Journal of Aviation/Aerospace Education \& Research, 13(3). https://doi.org/10.15394/jaaer.2004.1541

This Article is brought to you for free and open access by the Journals at Scholarly Commons. It has been accepted for inclusion in Journal of Aviation/Aerospace Education \& Research by an authorized administrator of Scholarly Commons. For more information, please contact commons@erau.edu. 


\title{
ADAPTION AND INNOVATION IN FLIGHT TRAINING-THE BENEFITS OF COGNITIVE DIVERSTTY
}

\author{
R. Kurt Barnhart
}

\begin{abstract}
This article highlights how differences in cognitive style paradigms, according to Adaption-Innovation (A-I) Theory, can have a positive impact in a flight training environment. This study examined twenty-four pairs of flight instructors and primary flight students who retained this relationship throughout the student's entire primary flight training experience; through to their initial U.S. civilian pilot certification, the private pilot's certificate. Dr. Michael Kirton's Adaption-Innovation Theory of cognitive style was used as the cognitive style paradigm. The instrument associated with A-I theory measures an individual's cognitive style preference on a numeric horizontal scale ranging from highly adaptive on the left to highly innovative on the right. The instrument yields four scores altogether, a main score, and three sub-scale scores: sufficiency of originality, efficiency, and rule/group conformity scores, all indicated along the adaptive-innovative scale (with different ranges). This study examined the effect that cognitive gap (differential scores between two individuals in this case) had on the flight training relationship between flight instructor and student. A gap on the third sub-scale score, rule/group conformity was found to have a significant impact on flight training efficiency, as measured by time spent in flight training until the private pilot check ride was passed by the student. It was found that significantly different scores on this scale led to a reduction in flight training time while similar scores led to an increase in time spent in flight training. The findings suggest there is a tangible benefit to some cognitive diversity in the flight training process.
\end{abstract}

In recent years the field of aviation has increasingly realized the important influence that personality may have on the way aviation professionals perform their jobs. In particular personality interaction on the flight deck of an aircraft has been demonstrated to have a substantial impact on the safe outcome of a flight (Kern, 1998). Both the military and commercial airlines have launched major training initiatives designed to better understand the human element of flight safety (Jensen \& Biegelski, 1989). However, relatively little is known about how personality interactions impact flight crew interactions. Many authors are calling for increased exploration into the implications personality and personality interactions have for aviation in general and for aviation flight instruction specifically. According to noted aviation researchers Foushee and Helmreich, personality inventories have long been used in aviation to screen out "psychopathology" and too little attention has been paid to measures that affect interaction (1988). Others in aviation psychology are calling for the increased use of personality measures with less focus on intelligence measures (Martinussen, 1996).

One of the most significant flight crew interactions in the aviation higher education environment occurs in the initial flight instructor-student relationship, where new aviation students are paired with a flight instructor and flight training is commenced in the aircraft for the first time. Effective interaction here has long-term implications for a student's personal safety and career success. It is this relationship that will be examined in order to ascertain what more knowledge of a very specific dimension of student and instructor personalities might tell us about the effectiveness of the instruction that occurs in that relationship.

The personality characteristics of pilots have been measured using a number of inventories that were either developed for use specifically with pilots or adapted from other areas. Three measures are the Eysenck Personality Indicator (EPI), the Cockpit Management Attitudes Questionaire (CMAQ), and the Temperament Structure 
Scale (TSS) (Retzlaff \& Gibertini, 1988; Jurgen-Hormann \& Machke, 1996). It has been established by Foushee \& Helmreich (1988) and Martinussen (1996) that many of these measures are used to screen out "psychopathology" or measure intelligence rather than fostering awareness of pilot interaction issues.

\section{A-I Theory}

Another way to examine the role personality plays in the aviation flight-training environment is to look at the concept of cognitive style. In his book outlining the Adaption-Innovation (A-I) theory of cognitive style, Dr. Michael Kirton (1994a) describes cognitive style as one "basic dimension of human personality" consisting of an individual's preferred mode of addressing problems, resolving them and implementing those solutions. The process of flying an aircraft, including flight instruction, involves a continuous series of problems and their implemented solutions largely played out in a team environment. Consequentially, an individual's cognitive style, as defined by Kirton, plays a major role in the flight instruction environment.

Kirton describes preferred cognitive style in terms of adaption and innovation. Those who have adaptive preferences prefer a greater amount of structure as they approach and deal with problems while those who have innovative preferences prefer less structure. Within the theory this preference for structure lies along three basic dimensions:

1. Style of originality $(\mathrm{S} / O)$ relates to an individual's preference to generate original ideas in problem solving. Individual's whose style is more adaptive prefer to generate a limited number of novel or original ideas and to focus on those which they consider to be the most effective. Those with a more innovative style prefer to proliferate ideas until the most novel approach is found.

2. Style of Efficiency (E) which relates to an individual's preference for organizational or system structure as it relates to accomplishing a task. The more adaptive preference here is to work within a given structure to attempt to solve problems within that structure while the more innovative preference here is to work outside or push the limits of the existing structure is order to achieve problem solution.

3. Style of Rule/Group Conformity (R) which relates to operating within the confines of organized rules, norms and group consensus. The more adaptive preference is to attempt to solve problems within the confines of existing rules and procedures, while the more innovative preference is to go outside the rule boundaries to achieve resolution.

As individuals interact and solve problems in their daily environment they operate within their preferred cognitive style and tend to seek out groups and interact with people who exhibit the same style (Kirton 1994b). If an individual is required to operate outside of the preferred style by being a member of a particular group, or being forced to work with an individual with a different preferred style, he or she may need to employ "coping behaviors" which require a great deal of effort and therefore stress for the individual. Thus it can be said that coping behavior is relatively expensive from a psychological standpoint (Kirton, 1994a). It has been shown that if this difference in mean KAI score differs by at least one standard deviation or more, coping behaviors will have to be "turned on" potentially causing either the potential for communication difficulty and interpersonal conflict, or providing for an increased breadth of problem solving ability if the gap is effectively managed (Kirton 1999c).

The differences in cognitive style preferences are known as cognitive gaps and must be managed in order for there to be effectiveness in dealing with the original problem. Cognitive gaps that are not recognized and effectively managed may lead to frustration of the original effort and at times, the complete disfunctionality of the group if the gap is managed poorly. Note that cognitive gaps can exist between two people, two groups of people, between a person and a group of people, or between a person and the requirements for a particular task. It is established in the literature that when work teams are heterogeneous in the areas of problem solving and communication, creative productivity and task efficiency is enhanced, thus, there can be a marked benefit to well managed cognitive gaps (Lattimer 1998).

Some basic and underlying assumptions of Dr. Kirton's Adaption-Innovation theory include:

1. All individuals have a preferred cognitive 
style which is not necessarily always linked to their observed behavior. An individual may often be required by their situation or environment to behave in ways which are contrary to their preferred style. This process in known as coping behovior and all individuals must engage in coping behavior at different times in their lives, the degree to which depends upon their own preferred style and the requirements of the particular situation.

2. It is important to draw a clear distinction between cognitive style and cognitive capacity. Cognitive capacity is often described in terms of "high" and "low" relating to one's cognitive ability such as I.Q. level. Cognitive capacity is usually measured along a vertical scale with high considered as preferable and visa versa. Cognitive style is often thought of as being measured on a horizontal continuum from left to right in non-pejorative terms as it relates to one's preferences. This is similar to a left-handed person preferring to work with the left hand as opposed to a righthanded person.

3. Change is a constant process which all individuals must be attuned to and in this process each individual will bring their own preferred cognitive style to bear in response to that change.
4. A-I theory embraces the concepts that creativity, problem solving, and decision making are all concepts which are closely related to cognitive style and all human beings engage in, and are adept at, all three according to their own preferred cognitive style.

5. All human-driven change implies some degree of structure. An absence of all structure is chaos. The distinction in A-I theory is the amount of structure preferred by a given individual in order to function.

Little has been written in the literature regarding cognitive style and its impact in the aviation environment; however, the importance of the study of cognitive style in the teaching environment is well documented in other fields such as that of nursing education. Nursing education is similar to aviation training in that much of the required training for nursing is done in a "hands-on" clinical setting often using separate "clinical faculty." Referring to nursing education, Rosenbloom (1980) wrote that

"Cognitive style can be used as a means for diagnosing the way an individual comes to know. In addition it provides direction for prescribing specific activities that would provide the individual with a high probability for success in a specified learning situation."

Table one gives some basic characteristics of adaptors and innovators as related to A-I theory: 
Table 1

Characteristics of adaptors and innovators

\begin{tabular}{|l|l|l|}
\hline & ADAPTORS & INNOVATORS \\
\hline Perceived Behavior & $\begin{array}{l}\text { Sound, conforming, safe, } \\
\text { predictable, inflexible }\end{array}$ & $\begin{array}{l}\text { Glamorous, exciting, unsound, } \\
\text { impractical, risky }\end{array}$ \\
\hline In Problem Definition & $\begin{array}{l}\text { Accept as defined, prefer to } \\
\text { limit disruption, need to see } \\
\text { short term benefit }\end{array}$ & $\begin{array}{l}\text { Reject generally accepted } \\
\text { definitions, look at long term } \\
\text { gains }\end{array}$ \\
\hline In Solution Generation & $\begin{array}{l}\text { Prefer a few novel, relevant and } \\
\text { acceptable solutions aimed at } \\
\text { improving what's existing }\end{array}$ & $\begin{array}{l}\text { Prefer numerous ideas possibly } \\
\text { not appearing relevant, prefer } \\
\text { to do things differently }\end{array}$ \\
\hline In Policy Formulation & $\begin{array}{l}\text { Prefer well established, } \\
\text { structured situations- good at } \\
\text { incorporating new ideas into } \\
\text { established situations }\end{array}$ & $\begin{array}{l}\text { Prefer less structured } \\
\text { situations- use new ideas to } \\
\text { create new structures- accept } \\
\text { greater risk }\end{array}$ \\
\hline In Organization & $\begin{array}{l}\text { Essential for ongoing functions } \\
\text { but have difficulty with change } \\
\text { in moving out of existing } \\
\text { functions }\end{array}$ & $\begin{array}{l}\text { Essential in times of change but } \\
\text { have trouble applying } \\
\text { themselves to ongoing } \\
\text { organizational demands }\end{array}$ \\
\hline
\end{tabular}

In Collaboration

\begin{tabular}{|l|l|l|l|}
\hline The Principle & $\begin{array}{l}\text { Groups need both } \\
\text { adaptors and } \\
\text { innovators to be } \\
\text { effective over time }\end{array}$ & Small Gaps & $\begin{array}{l}\text { The narrower the } \\
\text { thinking diversity } \\
\text { range, the more } \\
\text { limited the range of } \\
\text { problem solving } \\
\text { potential; within } \\
\text { this range high } \\
\text { efficiency is the } \\
\text { norm }\end{array}$ \\
\hline Problem of Large Gaps & $\begin{array}{l}\text { The larger the gap } \\
\text { between people's } \\
\text { scores on the KAI,the } \\
\text { greater the problem } \\
\text { communicating and } \\
\text { collaborating even if } \\
\text { both are adaptors or } \\
\text { innovators, it is the } \\
\text { gap size which is the } \\
\text { problem not location } \\
\text { on the scale }\end{array}$ & Bridgers & $\begin{array}{l}\text { Those who happen } \\
\text { to have an } \\
\text { intermediate score } \\
\text { within a group- may } \\
\text { be helpful in } \\
\text { bridging the gap } \\
\text { between two sides }\end{array}$ \\
\hline
\end{tabular}




\begin{tabular}{|l|l|l|l|}
\hline $\begin{array}{l}\text { The Advantage of Large } \\
\text { Gaps }\end{array}$ & $\begin{array}{l}\text { The wider the } \\
\text { difference the more } \\
\text { effort and tolerance is } \\
\text { needed to stay } \\
\text { together but the } \\
\text { greater is the group's } \\
\text { breadth of problem } \\
\text { solving }\end{array}$ & Coping Behavior & $\begin{array}{l}\text { Allows people to } \\
\text { play successfully a } \\
\text { role to which they } \\
\text { are not naturally } \\
\text { suited- creates stress } \\
\text { and is difficult over } \\
\text { long periods }\end{array}$ \\
\hline & Leadership & $\begin{array}{l}\text { Good leaders ask for } \\
\text { minimum coping } \\
\text { behavior most of the } \\
\text { time and get offered } \\
\text { maximum coping } \\
\text { behavior in a crisis }\end{array}$ \\
\hline
\end{tabular}

\section{The Inventory}

The Kirton Adaption-Innovation Inventory (KAI) is a thirty-two item inventory which was developed to test the theory and has been in continuous use for nearly thirty years. It consists of a series of items, each asking the individual to respond to situations which are aimed at measuring any one of the three factor traits which comprise the theory. The person taking the inventory is asked to place an $X$ along a seemingly continuous scale ranging from "very hard" to "very easy" in response to how that individual feels it is to present him/herself in the situations described. The inventory takes only a few minutes to complete and is then scored by the trained KAI administrator. The reliability and validity of the KAI have all been well proven across gender, age, and cultural boundaries (Kirton, 1994d).

\section{Purpose of the Study}

To examine the impact that cognitive gap, as defined by A-I theory, has in the flight instruction environment, specifically, how it impacts flight training efficiency as measured by time spent in flight training.

\section{Research Ouestion}

What is the effect of cognitive gap on flight time spent in initial civilian flight training?

\section{Population and Sample Selection}

Resource and access factors necessitated the use of a convenience sample consisting of 200 current and former students (alumni) of Indiana State University's Professional Pilot Program and their respective flight instructors be accomplished either through the U.S. mail or in a classroom setting. The Indiana State University professional pilot program represents an average size undergraduate pilot education program in the United States with approximately 200 current students, approximately half of which have the necessary credentials to participate in this study. Of these 200 students, approximately $80 \%$ are the professional pilot majors that were sought in this study. The remainders are aerospace administration majors. The private pilot certification exam is usually passed during the freshman year of study is such a program, and thus survey respondents will most likely be second through fourth year students (those having already passed the private pilot certification exam). Flight instructors in this program (as in many other programs) are most often recent graduates of the professional pilot program who remain on to teach prior to getting hired for a regular flight position with an airline or other corporation. The survey was administered to approximately 100 current students in a classroom setting, with the rest, approximately 100 more, being the most recent alumni contacted through the U.S. mail. In addition, the flight instructors were also contacted through the U.S. mail. This resulted in 347 student pilots and their respective flight instructors being surveyed.

\section{Respondent Information}

The Data Collection yielded 164 responses of 347 surveys distributed for a response rate of 47 percent. This number was slightly higher for student respondents and slightly lower for the flight instructor respondents due to the fact that it was sometimes difficult to get current addresses for the flight instructors. There were thirty flight instructors and 134 student respondents (some flight instructors had more than one student in the study). Twenty-four pairs of students and instructors could be used for this study in that the initial flight instructor and 
respective student remained together throughout the entire civilian primary flight training experience. Of these respondents the average age was Thirty years. Ninety-two percent of the respondents were male and seven percent were female. Approximately 100 of the student responses were current students, the rest were alumni.

Results

The results are summarized in Table 2.

Table 2 Gap Effects

\begin{tabular}{|c|c|c|c|}
\hline Score & $\mathbf{N}$ & $\begin{array}{l}\text { Mean Total } \\
\text { Time to Solo }\end{array}$ & $\begin{array}{l}\text { Mean Total Time to } \\
\text { Initial Certification }\end{array}$ \\
\hline $\begin{array}{l}\text { Overall Score } \\
\text { No Gap }\end{array}$ & 9 & 16.20 & 60.75 \\
\hline Overall Score ${ }^{2}$ Gap & 15 & 16.50 & 59.94 \\
\hline S/O Score No Gap & 12 & 12.00 & 61.00 \\
\hline S/O Score Gap & 12 & 15.87 & 58.50 \\
\hline E Score No Gap & 22 & 17.60 & 56.78 \\
\hline E Score Gap & 2 & 10.00 & 41.00 \\
\hline R Score No Gap & 16 & 17.7 & $63.9^{2}$ \\
\hline R Score Gap & 8 & 15.2 & $52.4^{2}$ \\
\hline $\begin{array}{l}\text { Overall Paired } \\
\text { Population }^{2}\end{array}$ & 134 & 18.60 & 66.70 \\
\hline $\begin{array}{l}\text { All Pairs Remaining } \\
\text { Together } \\
\text { Throughout Training }\end{array}$ & 24 & 16.50 & 59.50 \\
\hline
\end{tabular}

${ }^{1} \mathrm{Gap}=10$ points or greater score difference (just noticeably different scores)

${ }^{2}$ sig. $t(21)=-2.5, p=.018$ at .05

The significant findings from this study are centered on the rule/group conformity (R) score. Notice in table two that when there is no $\mathrm{R}$ score gap between student and instructor, training time increases on both measures (time to solo and time to initial certification test passage), and with an $\mathrm{R}$ score gap, the training time decreases on both measures. Notice also that the difference is directionally consistent on both measures and is significant for the "mean total time to initial certification" measure. Discussion and Recommendations or Future Research As was stated earlier in the section on A-I theory, when cognitive gaps are present, there exists both the 
potential for greater conflict if the gap is not properly managed, as well as the potential for increased efficiency due to the advantages of diverse cognitive processes in problem solving. Thus far, the literature has only investigated cognitive gaps as they relate to overall KAI scores, not gaps related to sub-scale scores. This research seems to be one of the first suggestions that observable cognitive gap effects are found between two individual's sub-scale scores.

Note from the earlier discussion of the rule/group conformity scores, that adaptive R's tend to be more concerned with group cohesion and with working within a given set of boundaries while innovative $R$ 's tend to be less concerned with such things. As was mentioned earlier, cognitive diversity leads to improved group efficiency and problem solving. It therefore seems, that in this flight instructor-student relationship, the more innovative $R$ in the group is widening the perceived (by the more adaptive R) operational/environmental boundaries thereby allowing the more adaptive $\mathrm{R}$ to draw from a larger "tool bag" as they, with their increased ability to work within group norms, function in the highly structured flight training environment. In the researcher's own experience as a flight instructor there have been several instances where training "breakthroughs" have occurred when either the student or the instructor have been made aware of, or reminded, by the other, of different procedures and/or techniques which have served to expedite the teaching/learning process for a particular student.

While more research is clearly needed to determine if this characteristic is found to be consistent across a variety of situational and cultural boundaries, the researcher believes that the directional consistency (larger gaps produce reduced training time and visa versa) and consistency across both measures of training efficiency (time to solo flight and time to initial certification) serve as a good basis for at least making this a point of awareness in the flight training environment.t

R. Kurt Barnhart is an assistant Professor of Aerospace Technology at Indiana State University. He holds a commercial pilot certificate with instrument, multi-engine, seaplane and glider ratings. He also is a certified flight instructor with instrument and multi-engine ratings. In addition Dr. Barnhart holds an airframe and powerplant license with inspection authorization. Dr. Barnhart holds an A.S. in Aviation Maintenance Technology from Vincennes University, a B.S. in aviation administration from Purdue University, an MBAA from Embry-Riddle Aeronautical University, and $\mathrm{Ph}$.D. in educational administration from Indiana State University. His work experience includes work as a flight instructor, A\&P mechanic, R\&D inspector with Rolls Royce Engine Company, and instructor for American Trans-Air airlines, and Embry-Riddle Aeronautical University. 


\section{REFERENCES}

Hormann, Hans-Jurgen, \& Maschke, Peter. ( 1996). On the Relationship Between Personality and Job Performance of Airline Pilots. International Journal of Aviation Psychology, 6(2), 1996.

Jensen, Richard S., \& Biegelski, Conrad S., (1989). Cockpit Resource Management. In Jensen, Richard S. (Ed.), Aviation Psychology (pp. 176 - 178). Aldershot, U.K.: Grower Technical.

Kern, Tony (1998). Flight Discipline, New York, NY: McGraw-Hill

Kirton, M.J. (1994). A Theory of Cognitive Style. In M.J. Kirton (Ed.) Adaptors and Innovators, Styles of Creativity and Problem Solving. (pp. 1-33). New York, N.Y., Routledge.

Kirton, M.J. (1994). Adaptors and Innovators at Work. In M.J. Kirton (Ed.) Adaptors and Innovators, Styles of Creativity and Problem Solving. (pp. 51-71). New York, N.Y., Routledge.

Kirton, M.J. (1999) Kirton Adaption-Innovation Inventory Feedback Booklet.

Kirton, M.J. (1999) Kirton Adaption-Innovation Inventory Manual, $3^{\text {rd }}$. ed. Berkhamsted, U.K., Occupational Research Centre.

Lattimer, Robert L. (1998). The Case For Diversity in Global Business, and the Impact of Diversity on Team Performance. Competitiveness Review. 8 (2), 3 -15.

Martinussen, Monica. (1996). Psychological Measures as Predictors of Pilot Performance: A Meta-Analysis. The International Journal of Aviation Psychology, 6 (1), 1-20.

Retzlaff, Paul D., \& Gilbertini, Michael. (1988) Objective Psychological Testing of U.S. Air Force Officers in Pilot Training. Aviation Space and Environmental Medecin, July 1988.

Rosenbloom, L.L., (1980). Learning/teaching styles: cognitive mapping. Journal N.Y.S.N.A., 11, \#1, 32-41. 